\title{
Vagus nerve stimulation in the treatment of epilepsy
}

$\mathrm{D}$ espite the fact that 15 different antiepileptic drugs are now available for use in Canada, about one-third of patients with epilepsy continue to have inadequate seizure control. Patients with pharmacoresistant epilepsy often experience various side effects of drug therapy, and the failure to control seizures can have devastating psychosocial, economic and health consequences, including serious accidents and cognitive or behavioural deterioration. In a small proportion of patients the effects of the epilepsy are so severe as to warrant brain surgery (usually of the temporal lobe). Innovative approaches have therefore been sought, including the ketogenic diet for children, implanted deep-brain stimulators (under study) and vagus nerve stimulation (VNS), which was approved in the US and Canada in 1997.

\section{Why vagus nerve stimulation?}

In 1985 Zabara proposed that VNS might disrupt the hypersynchronous brain electrical activity that underlies epileptic seizures, and subsequent studies in animal models of epilepsy suggested that this was the case. Although the mechanism of ac- tion of VNS is still not fully understood, it was felt that continual stimulation of the vagus nerve by an implantable electrical device might result in widespread bilateral activation or deactivation of the brain circuits thought to be involved with epileptic seizures. The reason for this lies in the neuroanatomical connections: afferent fibres from the vagus nerve comprise about $80 \%$ of the axons in the cervical vagus nerve, terminating on nuclei in the ipsilateral medulla and in the contralateral nucleus of the tractus solitarius (also in the brain stem). Inputs to these nuclei are then conveyed to widespread bilateral areas of the cerebral cortex, diencephalon and limbic system. The effects of VNS on these brain areas has been confirmed by positron emission tomography and functional MRI studies. ${ }^{1}$ Vagus nerve stimulators are not on-demand devices like cardiac pacemakers, which are designed to abort an event. Rather, they mostly function interictally - that is, between seizures, producing long-term alterations in the brain and thus decreasing seizure frequency. These long-term changes are not fully understood, as the characteristic interictal spike frequently seen on the electroencephalogram is largely unchanged.

\section{Technique}

The VNS is a battery-powered device very similar to a cardiac pacemaker. The latest model weighs $25 \mathrm{~g}$ and measures $7 \mathrm{~mm}$ in depth and $52 \mathrm{~mm}$ in diameter. The body of the device is implanted in the upper chest; 2 connecting wires with electrodes are placed subcutaneously and attached to the left vagus nerve in the carotid sheath. The surgery takes about 1 hour under general anesthesia, and the patient is usually discharged within a day. The generator is programmed by a wand attached to a laptop computer and placed over the generator. The customary cycle is a $30-$ second stimulation at 5-minute intervals. The stimulation intensity is gradually increased over weeks so the patient can accommodate to the mild discomfort (there is usually a mild tingling sensation and at at times mild shock-like pain) and voice changes (resulting from recurrent laryngeal nerve stimulation).

The battery life is now up to 11 years, at which point the de-

Table 1: Major clinical trials of vagus nerve stimulation for epilepsy

\begin{tabular}{|c|c|c|c|c|c|c|}
\hline Study & $\begin{array}{c}\text { No.of } \\
\text { patients* }\end{array}$ & Type of trial & Outcome measures & Results & $p$ value & Comments \\
\hline $\begin{array}{l}\text { The Vagus Nerve } \\
\text { Stimulation } \\
\text { Group }^{2}\end{array}$ & 114 & $\begin{array}{l}\text { Randomized, parallel, } \\
\text { double blind } \\
\text { High } \dagger \text { v. low } \neq \\
\text { stimulation }\end{array}$ & $\begin{array}{l}\text { \% change in seizure } \\
\text { frequency compared } \\
\text { with baseline }\end{array}$ & $\begin{array}{l}-24.5 \% \text { in high } v . \\
-6.1 \% \text { in low } \\
\text { stimulation group }\end{array}$ & $<0.01$ & $\begin{array}{l}\text { Short-term } \\
\text { study }(14-w k \\
\text { treatment } \\
\text { phase) }\end{array}$ \\
\hline Handforth et $\mathrm{al}^{3}$ & 199 & $\begin{array}{l}\text { Randomized, parallel, } \\
\text { double blind } \\
\text { High } \dagger \text { v. low } \neq \\
\text { stimulation }\end{array}$ & $\begin{array}{l}\% \text { change in seizure } \\
\text { frequency compared } \\
\text { with baseline }\end{array}$ & $\begin{array}{l}-28 \% \text { in high } v . \\
-15 \% \text { in low } \\
\text { stimulation group }\end{array}$ & 0.04 & $\begin{array}{l}\text { Short-term } \\
\text { study (3-mo } \\
\text { treatment } \\
\text { phase) }\end{array}$ \\
\hline DeGiorgio et $\mathrm{al}^{4}$ & 195 & $\begin{array}{l}\text { Longitudinal } \\
\text { follow-up of patients } \\
\text { from Handforth study } \\
\text { High stimulation } \dagger\end{array}$ & $\begin{array}{l}\text { \% change in seizure } \\
\text { frequency at } 3 \text { and } \\
12 \text { mo compared with } \\
\text { pre-implant baseline }\end{array}$ & $\begin{array}{l}-34 \% \text { at } 3 \text { mo and } \\
-45 \% \text { at } 12 \text { mo }\end{array}$ & $\begin{array}{l}<0.0001 \text { at } \\
\text { both stages } \\
\text { compared with } \\
\text { pre-treatment } \\
\text { baseline }\end{array}$ & Unblinded \\
\hline
\end{tabular}

*All 3 studies involved adults with partial seizures with or without secondary generalization.

HHigh stimulation: current $0.25-3.0 \mathrm{~mA}$, frequency $20-50 \mathrm{~Hz}$, pulse width 500 microseconds, on time 30-90 seconds, off time 5-10 minutes.

fLow stimulation: current $0.25-2.75 \mathrm{~mA}$, frequency $1-2 \mathrm{~Hz}$, pulse width 130 microseconds, on time 30 seconds, off time $60-180$ minutes. 
ANALYSIS

vice needs to be replaced. The largest deterrent to the use of VNS is the cost of \$24000 for the newest units. In Canada, funding for VNS devices is limited.

\section{Efficacy and side effects}

Building on animal seizure models and pilot studies, 2 randomized clinical trials were conducted in patients with localization-related epilepsy in the 1990s; these trials used an "active placebo" design with lowintensity and high-intensity stimulation. ${ }^{2,3}$ A long-term follow-up study showed that efficacy was maintained and actually increased over time (Table 1). ${ }^{4}$

On the basis of modest but significant findings of efficacy and good safety results in these short-term trials, the device was approved by the FDA and Health Canada. About 25000 devices have now been implanted worldwide, including about 400 in Canada.

VNS reduced the frequency of seizures by $50 \%$ or more in $30 \%-40 \%$ of patients. Efficacy tends to increase over time in the first year; changing the stimulation parameters to a more rapid cycle may improve efficacy (and also shortens battery life). The technique appears to be effective in the prevention of both generalized and partial seizures and to be equally effective in pediatric (> age 2 ) and adult patients.

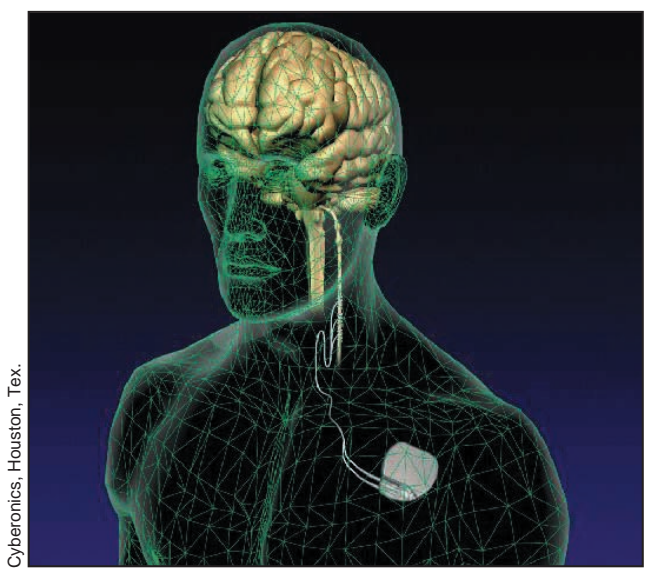

Vagus nerve stimulator in situ.
VNS has the distinct advantage of not depending on patient compliance: it functions automatically around the clock. However, it should be noted that patients rarely become seizurefree or able to eliminate their antiepileptic drugs entirely. VNS is therefore an adjuvant or palliative measure for patients in whom pharmacotherapy has proved inadequate, for whom traditional epilepsy surgery has failed or who are not candidates for traditional surgery.

Another advantage exists for patients who have auras as part of their seizures. Such patients can pass a magnet over the device during an aura to deliver an extra stimulation that may abort a full seizure (the magnet can also be taped over the device to turn it off if necessary). Other reported benefits include improvement in depression (a common problem in patients with epilepsy) and anecdotal claims for improved memory. Significant improvements in quality of life have been demonstrated with VNS.

The incidence of serious adverse events with VNS is low. ${ }^{6}$ Complications of the surgery such as wound infection and transient vocal cord paralysis occur in about $0.1 \%$ of cases. Although the left vagus nerve is used (because it has fewer parasympathetic fibres to the atria of the heart), transient sinus arrest may occur during testing of the device in the operating room. During the stimulation, patients often experience changes in voice quality or volume, and some experience neck, throat or ear pain, which may abate with a reduction in stimulation intensity or pulse width. The leads in the neck can occasionally break. A few patients complain of sleep disruption. There are reports of worsening of sleep apnea, and therefore the device is relatively contraindicated in patients known to have this problem. In severely mentally retarded chil- dren who need assistance for feeding, there is some evidence that the risk of aspiration may be increased during stimulation. MRI with a head coil is felt to be safe but diathermy is contraindicated.

\section{The place of VNS in epilepsy therapy}

As an adjuvant therapy VNS has comparable efficacy to most of the newer generation antiepileptic drugs, with a better sideeffect profile. The devices are expensive, limiting more widespread use. Although VNS does not replace pharmacotherapy or traditional epilepsy surgery, some patients have been able to reduce the number of drugs they need to take and their dosage. The cost-effectiveness of VNS remains to be determined; additional clinical trials are necessary to answer questions around patient selection and the types of seizures VNS is most effective in preventing.

\section{Alan Guberman}

Division of Neurology

The Ottawa Hospital

Ottawa, Ont.

Competing interests: None declared.

\section{References}

1. Henry TR. Therapeutic mechanisms of vagus nerve stimulation. Neurology 2002;59(Suppl 4):S3-S14.

2. A randomized controlled trial of chronic vagus nerve stimulation for treatment of medically intractable seizures. The Vagus Nerve Stimulation Study Group. Neurology 1995;45: 224-30.

3. Handforth A, DeGiorgio CM Schachter SC, Uthman BM, Naritoku DK, Tecoma ES, et al. Vagus nerve stimulation therapy for partial-onset seizures: a randomized active-control trial. Neurology 1998;51(1):48-55.

4. DeGiorgio CM, Schachter SC, Handforth A, Salinsky M, Thompson J, Uthman B, et al. Prospective longterm study of vagus nerve stimulation for the treatment of refractory seizures. Epilepsia 2000;41(9):1195-200.

5. Wheless JW, Maggio V. Vagus nerve stimulation therapy in patients younger than 18 years. Neurology 2002;59(6 Suppl 4):S21-S25.

6. Schachter SC.Vagus nerve stimulation therapy summary: five years after FDA approval. Neurology 2002:59(6 Suppl 4):S15-S20. 